Quarterly Progress Report For: Replacing Chemicals in Recycle Mills with Mechanical Alternatives

Covering Period: July 1, 1999 to September 30, 1999

Date of Report: October 14, 1999

Contractor: Institute of Paper Science and Technology Award Number: DE-FC36-99GO10381

Contact: Sujit Banerjee (404) 894-9709; s.banerjee@ipst.edu

Project Team: DOE-HQ contact (Valri Robinson), AF\&PA contact (Conni Kunzler), project mentor (Tom Friberg, Weyerhaeuser, Jim Ramp, Southeast Paper).

Project Objective: The objective of this project is to explore potential applications of underwater pulsed power technology to the paper industry. These included fiber refining, disinfection, stickies dispersion, and stickies control.

Background: In pulsed power a spark is discharged underwater. Present commercial applications of the technology include the detonation of land mines, zebra mussel control, and water disinfection. In preliminary work we have found that stickies are rapidly dispersed under the influence of pulsed power. The purpose of this project is to explore other applications of the technology in the recycle paper industry, especially in applications where the technology can replace potentially expensive chemical use.

Status: We have found that sparking in the presence of hydrogen peroxide induces some pulp bleaching. A 2,000V pulse provides the same effect as the 6,500V pulse used earlier, which should allow increase of the repetition rate and improve throughput. Sparking increases the screenability of PSAs, which could be important in removing stickies at the front end. Some stickies such as Robond, a PSA used in the paint industry, are relatively unaffected by spark treatment. However, this polymer is cross-linked to a greater degree, which could be a contributing factor. Stickies are also oxidized by ultrasound through hydroxyl radicals. Since sonolysis and sparking lead to similar (but not identical effects), hydroxyl radical oxidation is also probably involved during sparking. Work with a Fricke dosimeter suggests that hydroxyl radicals are probably generated locally by the propagating shock wave, and not just in the plasma region. A provisional patent has been filed. A licensing agreement with Sparktec Environmental, Stoney Creek, Canada, the manufacturer of the device, is being negotiated. Several companies have been contacted for field trials. We expect to firm up a schedule in late 1999.

Details are provided in the Attachment. 


\section{DISCLAIMER}

This report was prepared as an account of work sponsored by an agency of the United States Government. Neither the United States Government nor any agency thereof, nor any of their employees, make any warranty, express or implied, or assumes any legal liability or responsibility for the accuracy, completeness, or usefulness of any information, apparatus, product, or process disclosed, or represents that its use would not infringe privately owned rights. Reference herein to any specific commercial product, process, or service by trade name, trademark, manufacturer, or otherwise does not necessarily constitute or imply its endorsement, recommendation, or favoring by the United States Government or any agency thereof. The views and opinions of authors expressed herein do not necessarily state or reflect those of the United States Government or any agency thereof. 


\section{DISCLAIMER}

Portions of this document may be illegible in electronic image products. Images are produced from the best available original document. 


\section{Plans for the Next Quarter:}

- Study the mechanism of stickie detackification.

- Identify the nature of the oxidizing species, and determine whether there is more than one pathway for detackification.

- Determine the boundaries of the process; i.e. which stickies can be oxidized and why.

- Plan field trials.

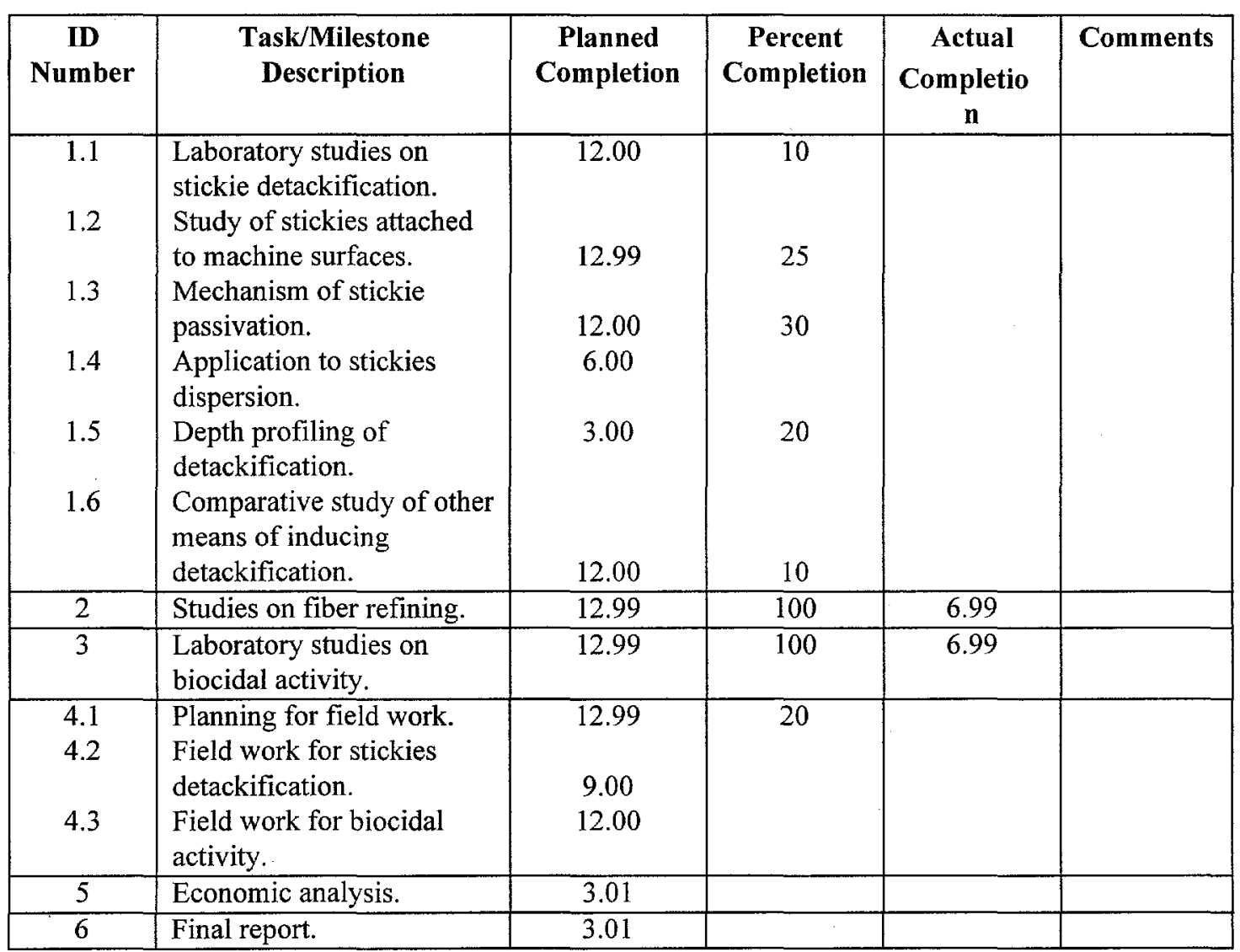




\title{
Replacing Chemicals in Recycle Mills with Mechanical Alternatives
}

(DE-FC36-99G010381)

\author{
Dong-Jin Sung, Howard Corcoran, Sujit Banerjee \\ Institute of Paper Science \& Technology
}

Progress Report No. 4, September 1999

Summary

- Sparking in the presence of hydrogen peroxide induces some pulp bleaching.

- A 2,000V pulse provides the same effect as the $6,500 \mathrm{~V}$ pulse used earlier. This should allow increase of the pulse repetition rate and improve throughput.

- The increase in PSA screenability during sparking has been confirmed.

- Robond, a PSA used in the paint industry, is unaffected by spark treatment. However, Robond is cross-linked to a greater degree, which could be a contributing factor.

- Work with a Fricke dosimeter suggests that hydroxyl radical generation is independent of volume in the 2.5-35 gallon range. Hence, hydroxyl radicals are probably generated locally by the propagating shock wave, and not just in the plasma region.

- Kinetic work has shown that sonication leads to hydroxyl radical generation. Since stickie detackification occurs by both by ultrasound through the hydroxyl radicals generated. Since ultrasound and sparking lead to similar (but not identical effects), hydroxyl radical oxidation is also probably involved during sparking.

- A provisional patent has been filed. A licensing agreement with Sparktec Environmental, Stoney Creek, Canada, the manufacturer of the sparker, is being negotiated.

- Several companies have been contacted for field trials. We expect to firm up a schedule in late 1999.

\section{Effect of sparking on the surface energy of Carbotac}

In the preceding report we demonstrated that sparking reduced the tack and increased the surface energy of a Carbotac latex pressure sensitive adhesive (PSA). We have generally confirmed these results, and spark-induced changes in the surface energy of the PSA (supported on a metal plate) are reported in Table 1. Under most treatment conditions, the surface energy rose by 2 to 7 dynes $/ \mathrm{cm}$, which was smaller than that observed before. However, the surface energy of the control was also much higher, and we ascribe the lower tack reduction to the lower starting tack of the sample. We had previously found that sparking increased the $\mathrm{O}: \mathrm{C}$ ratio of the polymer surface, indicating that the surface was oxidized. We reasoned that sparking in the presence of hydrogen peroxide could enhance the process by enhancing radical generation. The presence of peroxide did increase the surface energy, but XPS analysis of the treated polymer showed that the $\mathrm{O}: \mathrm{C}$ ratio inexplicably remained unchanged at 0.30 . If taken at face value, this means that an increase in the $\mathrm{O}: \mathrm{C}$ ratio is not required for detackification.

In a related experiment, unbleached Kraft softwood pulp (kappa 75) was sparked 60X and 100X, in 3\% hydrogen peroxide. After one hour, bleached fibers were seen in both the $60 \mathrm{X}$ and 100X sparked samples. Bleaching did not occur in the absence of sparking. 


\section{Effect of sparking and ultrasonic treatment on the surface energy of pure acrylates}

In order to explore the effect of sparking on other acrylates, four pure polymer films were formed on metal plates and sparked in the 2.5 -gallon tank. Three samples showed a 5 dynes $/ \mathrm{cm}$ increase in surface energy upon sparking (Table 2); the fourth showed a slight decrease in surface energy. The O:C ratio was measured by XPS for two samples; both were unchanged. We interpret the results to indicate that the process applies to acrylates other than just Carbotac, but not to all polymers. Again, an increase an increase in $\mathrm{O}: \mathrm{C}$ ratio does not appear to be essential.

\begin{tabular}{|c|c|c|c|}
\hline & no. of sparks & $\begin{array}{c}\text { surface energy } \\
\text { (dynes } / \mathrm{cm})\end{array}$ & O:C ratio \\
\hline $45^{\circ} \mathrm{C}$ & 0 & 22.4 & $0.29,0.30$ \\
\hline $45^{\circ} \mathrm{C}$, towards spark & 40 & 24.7 & $\overline{0.32}$ \\
\hline $45^{\circ} \mathrm{C}$, away from spark & 40 & 25.4 & 0.32 \\
\hline $45^{\circ} \mathrm{C}, 0.1 \%$ retention aid ${ }^{3}$ & 0 & 25.4 & \\
\hline $45^{\circ} \mathrm{C}, 0.1 \%$ retention aid ${ }^{3}$ & 40 & 26.8 & \\
\hline $45^{\circ} \mathrm{C}, 0.1 \%$ surfactant ${ }^{4}$ & 0 & 23.8 & \\
\hline $45^{\circ} \mathrm{C}, 0.1 \%$ surfactant $^{4}$ & 40 & 25.7 & \\
\hline $22^{\circ} \mathrm{C}, 0.1 \%$ peroxide & $\overline{0}$ & 22.3 & \\
\hline $22^{\circ} \mathrm{C}, 3 \% \mathrm{H}_{2} \mathrm{O}_{2}$ & 20 & 26 & \\
\hline $22^{\circ} \mathrm{C}, 3 \% \mathrm{H}_{2} \mathrm{O}_{2}$ & 40 & 27.5 & 0.30 \\
\hline $22^{\circ} \mathrm{C}, 3 \% \mathrm{H}_{2} \mathrm{O}_{2}$ & 60 & 26.6 & \\
\hline $22^{\circ} \mathrm{C}$ & $\overline{0}$ & 19.4 & \\
\hline $22^{\circ} \mathrm{C}$ & 40 & 25.7 & \\
\hline $22^{\circ} \mathrm{C}$ & 60 & 28.2 & \\
\hline
\end{tabular}

\begin{tabular}{|l|c|c|c|}
\hline Table 2: Effect of sparking on the surface energy of PSAs \\
\hline & $\begin{array}{c}\text { no. of } \\
\text { sparks }\end{array}$ & $\begin{array}{c}\text { surface energy } \\
\text { (dynes/cm) }\end{array}$ & O:C ratio \\
\hline poly(iso-butyl acrylate) & $0 \mathrm{X}$ & 10.1 & 0.31 \\
\hline poly(iso-butyl acrylate) & $40 \mathrm{X}$ & 15.9 & 0.31 \\
\hline poly(n-butyl acrylate) & $0 \mathrm{X}$ & 7.2 & \\
\hline poly(n-butyl acrylate) & $40 \mathrm{X}$ & 13.7 & \\
\hline poly(lauryl-acrylate) & $0 \mathrm{X}$ & 8.5 & \\
\hline poly(lauryl-acrylate) & $40 \mathrm{X}$ & 13.2 & \\
\hline $\begin{array}{l}\text { poly(methyl styrene- } \\
\text { co-indene) }\end{array}$ & $0 \mathrm{X}$ & 16.5 & 0.02 \\
\hline $\begin{array}{l}\text { poly(methyl styrene- } \\
\text { co-indene) }\end{array}$ & $40 \mathrm{X}$ & 15.5 & 0.02 \\
\hline \multicolumn{4}{|l}{} \\
\hline 'at $22^{\circ} \mathrm{C}, \mathrm{pH} 7$; $^{2}$ run by XPS at an incident angle of $38^{\circ}$. \\
\hline
\end{tabular}


In the preceding report we showed that detackification could also be induced, albeit much more slowly, by ultrasound. The results of experiments where the acrylates were sonicated for 40 minutes are provided in Table 3. Tack was measured with a Polyken tack tester on a $0.2 \mathrm{~cm}^{2}$ surface at a $100 \mathrm{~g} / \mathrm{cm}$. contact pressure, 1 second contact time, and a $1 \mathrm{~cm} / \mathrm{sec}$ withdrawal speed. The surface energy increased in all cases. A point of contrast is the behavior of poly(methyl styrene-co-indene) which is relatively unaffected by sparking, but is passivated by ultrasound. These measurements indicate that detackification is not universal, but depends upon the chemical structure, for reasons that are presently unknown.

\begin{tabular}{|l|c|c|c|c|}
\hline Table 3: Effect of sonication on various acrylates \\
\hline & \multicolumn{2}{|c|}{$\begin{array}{c}\text { surface energy } \\
\text { (dynes/cm) }\end{array}$} & \multicolumn{2}{|c|}{$\begin{array}{c}\text { tack (grams per 0.2 } \\
\mathbf{c m}^{\mathbf{2}} \mathbf{\text { ) }}\end{array}$} \\
\hline & control & treated & control & treated \\
\hline poly(2-ethylhexyl acrylate) & 8.5 & 8.8 & 514 & 503 \\
\hline poly(iso-butyl acrylate) & 11.4 & 23.2 & $>2,000$ & 1774 \\
\hline poly(lauryl acrylate) & 7.4 & 17.1 & 660 & 512 \\
\hline poly(n-butyl acrylate) & 7.0 & 12.2 & 908 & 643 \\
\hline poly(isoprene) & 12.8 & 21.2 & 457 & 342 \\
\hline polymethyl styrene-co-indene & 15.8 & 29.3 & not tacky at room temp \\
\hline
\end{tabular}

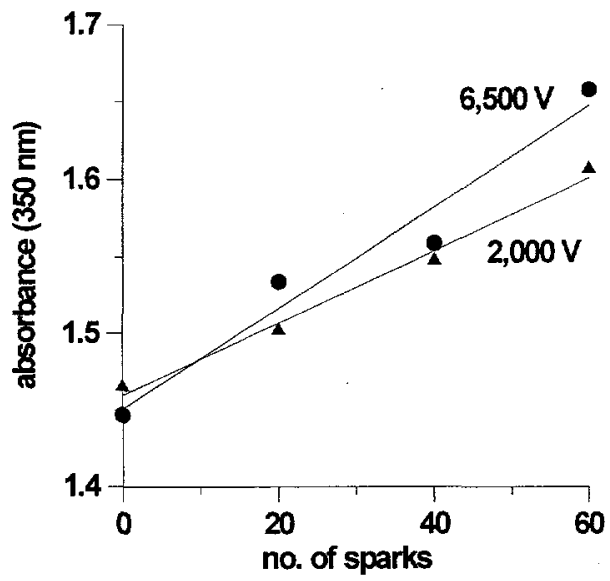

Figure 1. Effect of voltage on radical generation.

\section{Effect of voltage on hydroxyl radical yield}

In order to determine how the applied voltage influenced the generation of hydroxyl radicals, a Fricke dosimeter $\left(\mathrm{FeSO}_{4} ; 8.5 \times 10^{-3} \mathrm{M}\right.$, G.J. Price and E.J. Lenz, Ultrasonics, 31(6), 451-456, 1993) was sparked at 2,000 and $6,500 \mathrm{~V}$. The results, presented in Figure 1, show that the two conditions lead to similar increases in absorbance. Experiments with the dosimeter conducted in the 2.5 and 35-gallon tanks, showed that the resulting absorbance was very similar, suggesting that volume was not critical, at least over this range. Hence, the hydroxyl radicals are probably generated locally by the propagating shock wave, and not just in the plasma region.

\section{Screenability measurements}

A Carbotac emulsion was dried on glass plates and re-emulsified using a homogenizer with a small

amount of sodium silicate surfactant. The emulsion was diluted to $0.5 \%$ by weight in water, and sparked. Samples were run through a Pulmac shive analyzer with a $0.006 "(150 \mu)$ screen. The rejection percent increased from 59.1 (control) to $61.4(40 \mathrm{X})$ and $70.5(60 \mathrm{X})$. The above experiment was repeated in the presence of bleached kraft pulp of $1 \%$ consistency. The rejection percent was 59.1 (control), $61.3(40 \mathrm{X})$, and $63.4(60 \mathrm{X})$. Although the rejection efficiency dropped somewhat in the presence of pulp, sparking significantly improves screenability, as noted in the preceding report. 


\section{Effect of sparking and ultrasonic treatment of Robond}

Robond 51 and 90 are pressure-sensitive acrylates used in the paint industry, and their response to sparking was studied in order to extend our studies beyond Carbotac. The results, shown in Table 4, demonstrate that the changes in surface energy are relatively small. A possible difference between Carbotac and Robond is the degree of cross-linking, and we measured these values by extraction with the following solvents: THF, chloroform, 2-butanone, toluene, and methylene chloride, with the solvent being changed every 8 hours. The degree of crosslinking was calculated by the following equation (S.T. Wang et al., J. Appl. Polymer Sci., Vol. 60, 2069-2076, 1996):

percent degree of crosslinking $=100 \times$ (post-extraction weight/initial weight).

The results show that there is $80.9 \%$ crosslinked copolymer for Carbotac and $85.8 \%$ for Robond 90 PSA samples. It is possible that the greater degree of cross-linking of Robond 90 could contribute to its relative inertness. This will need to be confirmed.

\section{Sonication of stickies in the presence of pulp}

Stickies (Carbotac PSA and Robond PS-90) were coated on $4.5 \times 4.5 \mathrm{~cm}$ paper coupons (bleached softwood Kraft) at a level of $0.5 \mathrm{~g} /$ coupon. The coupons were sonicated in water and also in bleached pulp at $1.1 \%$ and $2.2 \%$ consistency. The tack decreased substantially for both stickies. For Carbotac, it decreased from 365 (control) to 247 (in water), $290(1.1 \%$ ), and 240 (2.2\%) grams $/ 0.2 \mathrm{~cm}^{2}$. For Robond 90 , the control was 471 , as compared to 364 in water, and 369 and 376 in $1.1 \%$ and $2.2 \%$ pulp, respectively. Hence, the presence of pulp does not significantly affect the decrease in tack induced by sonication.

In order to confirm that pulp did not inhibit radical generation, a $0.02 \mathrm{M} \mathrm{FeSO}_{4}$ solution was sonicated in the presence of $1.1 \%$ fiber. After 40 minutes, a handsheet (A) was made from

\begin{tabular}{|c|c|c|}
\hline & no. of sparks & $\begin{array}{c}\text { surface energy, } \\
\text { dynes } / \mathrm{cm}\end{array}$ \\
\hline \multicolumn{3}{|c|}{35 -gallon tank, $22^{\circ} \mathrm{C}, \mathrm{pH} 7,10 \mathrm{~cm}$ from spark } \\
\hline & 0 & 30.2 \\
\hline & 10 & 29.8 \\
\hline & 100 & 30.7 \\
\hline & 200 & 29.0 \\
\hline \multicolumn{3}{|c|}{35 -gallon, $22^{\circ} \mathrm{C}, \mathrm{pH} 7,50 \mathrm{~cm}$ from spark } \\
\hline & 0 & 29.7 \\
\hline & 5 & 29.5 \\
\hline & 10 & 30.5 \\
\hline \multicolumn{3}{|c|}{2.5 -gallon tank, $45^{\circ} \mathrm{C}$} \\
\hline $\mathrm{pH} 5$ & 10 & 31.4 \\
\hline pH 7 & 10 & 29.8 \\
\hline $\mathrm{pH} 10$ & 10 & 27.8 \\
\hline
\end{tabular}


the treated sample. Another handsheet (B) was made by sonicating the $\mathrm{FeSO}_{4}$ (without fiber) and mixing it with untreated fiber, and a third $(\mathrm{C})$ was prepared by mixing untreated chemical and fiber. There was a difference in color in the three handsheets. The color of handsheets $\mathrm{A}$ and $\mathrm{B}$ were a darker yellow as compared to that of handsheet $\mathrm{C}$. Brightness measurements (TAPPI Test Method T-452) showed that handsheets A and B to be of 55 and 56 percent brightness, respectively, whereas the brightness of handsheet $C$ was 60 percent.

\section{Ultrasonic treatment of polyvinyl acetate}

In the preceding report we noted that sparking induced an increase in the surface energy of polyvinyl acetate (PVAc). In order to determine whether a similar effect could be induced by sonication, the stickie was dissolved in acetone $(1: 2 \mathrm{w} / \mathrm{w})$, coated on a metal coupon to a thickness of about $0.1 \mathrm{~mm}$., and sonicated for 40 minutes. No change in surface energy was observed for a PVAc of MW: 500,000. However, the surface energy of a MW: 12,800 PVAc increased from 38.8 to $44.1 \mathrm{dyne} / \mathrm{cm}$, measured at room temperature. However, in a second trial the surface energy increased from only 40.6 to $41.7 \mathrm{dyne} / \mathrm{cm}$. The results are inconclusive at this point, and the experiments will be repeated.

\section{Kinetics of ultrasonic-induced oxidation}

In order to demonstrate that sonication led to the generation of hydroxyl radicals, the rates of ultrasonic-induced oxidation of several compounds were studied and compared to known oxidation rates with hydroxyl radicals. The diammonium salt of ABTS (2,2'-azinobis-(3ethylbenzthiazoline-6-sulphonate)) is known to be quantitatively oxidized by the hydroxyl radical with a rate constant of $1.2 \times 10^{10} 1 \mathrm{~mol}^{-1} \mathrm{~s}^{-1}$ (B.S.Wolfenden and R.L.Wilson, J. Chem. Soc., Perkin Trans. II, 805-12, 1982), and was used as a reference. The resulting radical cation ABTS $^{\bullet+}$, has a characteristic absorption at $415 \mathrm{~nm}$. ABTS (obtained from Sigma-Aldrich) was sonicated in $300 \mathrm{~mL}$ of water at a nominal frequency of $50 \mathrm{kHz}$. The temperature was maintained at $22^{\circ} \mathrm{C}$ by pumping $22^{\circ} \mathrm{C}$ water into a glass coil immersed in the ultrasonic bath. The solution was monitored at $415 \mathrm{~nm}$ over 60 minutes of sonication; the absorbance changes are illustrated in Figure 2.

The oxidation of the compounds in Table 5 were measured at $22^{\circ} \mathrm{C}$ by sonicating a mixture of the test compound and ABTS $\left(1 \times 10^{-4} \mathrm{M}\right)$. If $\mathrm{A}^{\circ}$ is the absorbance at $415 \mathrm{~nm}$ obtained by treating ABTS alone, and $\mathrm{A}$ is the corresponding absorbance upon sonicating the mixture, then

$$
A^{o} / A=1+k_{1}[S] / k_{2}[A B T S]
$$

where $k_{1}$ and $k_{2}$ are the oxidation rates of the test compound and ABTS, respectively. The results, shown in Table 5, compare well with literature values, confirming that the loss of material on sonication is due to hydroxyl radical induced oxidation. We will now conduct parallel sparking experiments.

\section{Degradation of butyl acrylate and acrylic acid}

Aqueous solutions of butyl acrylate ( $850 \mathrm{ppm})$ and acrylic acid (1300 ppm) were sonicated for 2 hours at $22^{\circ} \mathrm{C}$. The total organic carbon (TOC) concentration of butyl acrylate decreased from 850 to $40 \mathrm{ppm}$ while that for acrylic acid remained almost constant with a marginal decrease from 1,300 to $1,150 \mathrm{ppm}$. The solutions were extracted by dichloromethane, and 


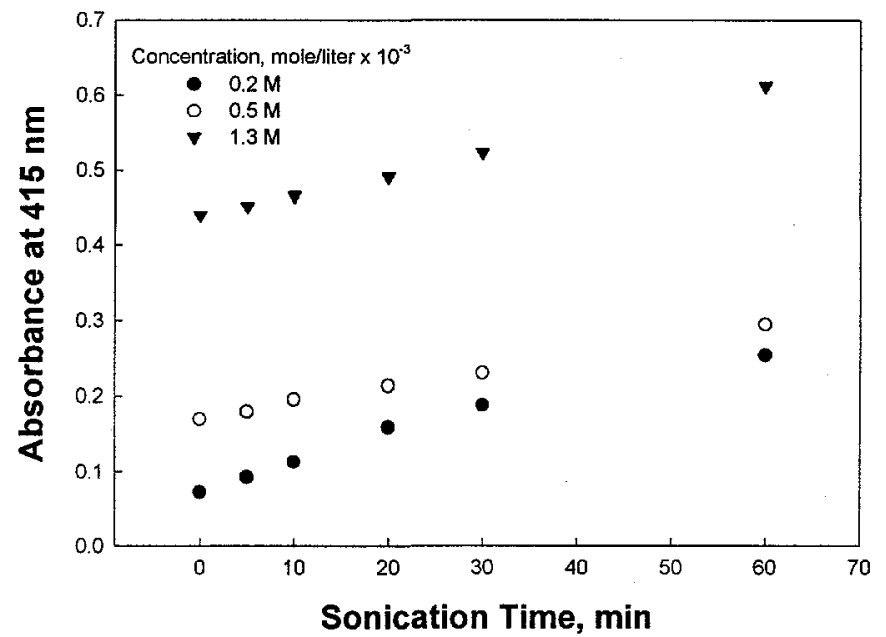

Figure 2: Absorbance changes upon sonicating ABTS

\begin{tabular}{|c|c|c|}
\hline \multicolumn{3}{|c|}{ Table 5: Rate constants of compounds using ABTS as reference } \\
\hline & $\begin{array}{c}\text { kx } 10^{-9}\left(1 \text { mol }^{-1} \mathrm{~s}^{-1}\right) \\
\text { measured }\end{array}$ & $\begin{array}{c}\text { kx 10 }{ }^{-9}\left(1 \mathrm{~mol}^{-1} \mathrm{~s}^{-1}\right) \\
\text { literature }\end{array}$ \\
\hline sodium formate & 4.8 & 3.2 \\
\hline thymine & 2.1 & 6.4 \\
\hline sodium acetate & 0.9 & 0.85 \\
\hline sodium thiocyanate & 10 & 11 \\
\hline
\end{tabular}

analyzed by gc/ms. No degradation products were observed. It is likely that the ester evaporated during sonication. Both sonicated solutions were also reacted with Schiff's reagent; no color change was observed suggesting that aldehydes were not generated. Some differences in the UV spectra of the solutions were observed. The absorbance of butyl acrylate at $291 \mathrm{~nm}$. increased from 0.000 to $0.039 \mathrm{AU}$, while that of acrylic acid decreased from 0.024 to zero. This suggests that the products formed are polar, which is consistent with our ability to detect them by gc/ms using a DB-17 column.

\section{Preparation for field trials}

The technology is close to the field-testing stage. Several presentations were made to industry, and Southeast Paper, Weyerhaeuser, Georgia-Pacific Corporation, Vattenfall (Sweden), and UPM-Kymmene (Finland) have expressed interest in field trials. We expect to firm up a schedule in late 1999.

\section{Technology transfer}

A provisional patent has been filed. A licensing agreement with Sparktec Environmental, Stoney Creek, Ontario, Canada, the manufacturer of the device, is being negotiated. 